\title{
Michael Shenkar. «The Religion and the Pantheon of the Sogdians (5th-8th Centuries CE) in Light of their Sociopolitical Structures »
}

\section{Alberto Bernard}

\author{
(2) OpenEdition \\ Journals \\ Édition électronique \\ URL : http://journals.openedition.org/abstractairanica/50857 \\ DOI : 10.4000/abstractairanica. 50857 \\ ISBN : 1961-960X \\ ISSN : 1961-960X \\ Éditeur : \\ CNRS (UMR 7528 Mondes iraniens et indiens), Éditions de l'IFRI
}

\section{Référence électronique}

Alberto Bernard, « Michael Shenkar. «The Religion and the Pantheon of the Sogdians (5th-8th

Centuries CE) in Light of their Sociopolitical Structures » », Abstracta Iranica [En ligne], Volume 40-41

2019, document 13, mis en ligne le 30 décembre 2019, consulté le 20 avril 2021. URL : http://

journals.openedition.org/abstractairanica/50857 ; DOI : https://doi.org/10.4000/abstractairanica. 50857

Ce document a été généré automatiquement le 20 avril 2021.

Tous droits réservés 


\title{
Michael Shenkar. «The Religion and the Pantheon of the Sogdians (5th-8th Centuries CE) in Light of their Sociopolitical Structures »
}

\author{
Alberto Bernard
}

\section{RÉFÉRENCE}

Michael Shenkar. « The Religion and the Pantheon of the Sogdians (5th-8th Centuries CE) in Light of their Sociopolitical Structures », Journal Asiatique 305.2, 2017, p. 191-209

1 En s'appuyant sur la comparaison avec d'autres cités-états, notamment grecques, l'A. indique une voie pour analyser la religion des Sogdiens - notion qu'il préfère à celle de «religion sogdienne». Certaines isomorphies (fragmentation politique, pluralité et variété des cultes locaux, absence d'un clergé centralisé) suggèrent à l'A. une réévaluation de certaines données problématiques. La proéminence de la déesse Nana serait ainsi limitée à Samarkand et à Penjikent. La distribution disproportionnée d'éléments iconographiques «zoroastriens » (présents sur des ossuaires, absents des peintures de Penjikent), s'expliquerait aussi par des différences régionales. Le troisième volet concerne les temples (Penjikent, Paykand, Nakhšab) et un sanctuaire (Jartepa-II) sogdiens, les premiers en tant qu'expressions cultuelles et associatives de la " communauté civique ", le deuxième comme partie émergée d'un réseau de lieux de pèlerinage. L'article se termine sur la suggestion que les prêtres sogdiens pouvaient en partie être des magistrats civiques. 


\section{AUTEURS}

\section{ALBERTO BERNARD}

Doctorant EPHE, Mondes iranien et indien, Paris 